\title{
Isolation frequency and susceptibility patterns of Nocardia species at a tertiary hospital laboratory in Karachi, Pakistan
}

\author{
Safia Bibi, Seema Irfan, Afia Zafar, Erum Khan \\ Department of Pathology and Microbiology, Aga Khan University Hospital, Karachi, Pakistan
}

Key words: Nocardia; sensitivity pattern; Co-trimaxazole; Pakistan

J Infect Dev Ctries 2011; 5(6):499-501.

(Received 9 June 2010 - Accepted 24 January 2011)

Copyright (C) 2011 Bibi et al. This is an open-access article distributed under the Creative Commons Attribution License, which permits unrestricted use, distribution, and reproduction in any medium, provided the original work is properly cited.

Nocardia species are ubiquitous, fine, soil-borne aerobic filamentous actinomycetes that are Gram positive and weakly acid fast [1]. Nocardiosis is an important opportunistic infection caused by Nocardia species. The infection most often occurs in immunocompromised individuals, especially those deficient in cell-mediated immunity but cases of nocardiosis have also been reported in some immunocompetent individuals [1,2]. Person-toperson transmission of Nocardia has not been reported in the literature and the organism is usually considered to be acquired from the environment $[1,3]$. Pulmonary nocardiosis and traumatically induced local abscesses are the common clinical manifestations of infection although rare cases of bacteremia, peritonitis, and corneal ulcers due to Nocardia species have also been reported [4-7]. Clinical diagnosis of nocardiosis is often difficult and misleading because of its relative low incidence and lack of pathognomonic symptoms $[1,8]$; hence the diagnosis is usually based on the isolation of the organism in pure culture from the affected area [9].

While many studies have been conducted worldwide to investigate the prevalence of nocardiosis in different regions [4,5,10], none have been performed in Pakistan; only limited individual case reports have been described from our country $[11,12,13]$. Our study was conducted to assess the frequency of infection by and sensitivity patterns of different Nocardia species isolated over a 15-year period at the Microbiology Laboratory of Aga Khan University Hospital, which is one of the leading tertiary care hospitals in Karachi. The Microbiology Laboratory services comprise a main clinical laboratory and a network of collection points all over Pakistan; hence the data represent patients throughout the country.

Cases of nocardiosis were identified using the hospital's computerized database for positive specimens submitted during the period 1990-2005, and reviewing the laboratory records of all these patients. Standard isolation and identification techniques as described by the American Society of Microbiology (ASM) were used for the diagnosis of nocardial infections [14]. Blood agar and chocolate agar were used for isolation, and identification was performed on the basis of colonial morphology, microscopic morphology (Gram stain and partial acid-fast stain) and biochemical tests (casein, tyrosine, xanthine and urea hydrolysis). Antimicrobial sensitivity was performed using the Kirby-Bauer disk diffusion method [15].

A total of 922,950 specimens were submitted to the laboratory, comprised of $497,533 \quad(53.9 \%)$ samples from males and 425,417 (46.1\%) samples from females. Nocardia species were isolated from $120(0.013 \%)$ clinical specimens.

A total of 120 cases of nocardiosis were observed during the 15-year period studied, showing an isolation frequency of eight cases per year. This isolation frequency is comparable to that of European countries [10,16,17], but it is quite low when compared to countries sharing similar climatic conditions as ours, such as Japan and parts of the United States [1,18]. One of the reasons for lower isolation rates in our study might be that clinical diagnosis of nocardiosis is often difficult and a strong degree of suspicion is required for proper diagnosis 
Table 1. Distribution of Nocardia spp. with respect to patient age.

\begin{tabular}{|c|c|}
\hline Age & n (\%) \\
\hline$<5$ years & $6(5.0 \%)$ \\
\hline $5-20$ years & $9(7.5 \%)$ \\
\hline $20-40$ years & $31(25.8 \%)$ \\
\hline $40-60$ years & $41(34.2 \%)$ \\
\hline$>60$ years & $33(27.5 \%)$ \\
\hline
\end{tabular}

[8]. Similarly, isolation of Nocardia species from clinical specimens requires a long incubation period so many cases may go unidentified when there is no early suspicion of nocardiosis by the clinician [8]. Recent reports also suggest an increasing incidence of nocardiosis [7], but in our study we observed 6-10 cases each year and the incidence remained almost constant throughout the 15-year study.

Eighty-three $(69 \%)$ samples that yielded the growth of Nocardia species were from hospitalized patients while the remaining 37 (31\%) samples were submitted to the laboratory through an outside referral. This higher isolation in hospitalized patients may reflect the severity of disease or the presence of some underlying conditions in patients which may be associated with the development of nocardiosis; however, as the clinical data of these patients could not be reviewed, this hypothesis could not be investigated.

Isolation of Nocardia was significantly higher (p-value $<0.05$ using chi-square test for comparison according to gender) in males (68\%) as compared to females $(32 \%)$. These findings are similar to most of the published literature $[6,10,16,17]$. No definitive explanation for this predominance in the male sex has yet been described but researchers believe that this could be due to hormonal effects on the virulence of organisms [1].

Patients ranged in age from less than one year to 95 years. The number of identified cases increased gradually with increasing age, with the maximum number of cases observed between the ages of 40-60 years. The number of cases declined in individuals older than 60 years of age (Table 1).

The clinical spectrum of nocardiosis was similar to that reported in the literature, with the respiratory tract cited as the most common site of isolation $(58.3 \%)$ followed by wound infections $(35 \%)$. Blood culture was positive in $3.3 \%$ cases while ocular nocardiosis was observed in $2.5 \%$. Cerebrospinal fluid (CSF) involvement was uncommon in our study and was seen only in one case $(0.8 \%)$. These findings are similar to the results of other studies except for the involvement of CSF which was lower in our study as compared to other studies [16-18].

Among 120 isolated strains of Nocardia, 87 $(72.5 \%)$ were identified as Nocardia asteroides, 13 $(10.8 \%)$ as Nocardia otitidiscaviarum and 11 (9.2\%) as Nocardia caviae. Nine (7.5\%) strains could not be identified to the species level using conventional methods. Similar distributions of Nocardia asteroides and Nocardia otitidiscaviarum are described elsewhere in the literature [1,16-18]. Nocardia caviae is not a common pathogen but in our study it was isolated in $9.2 \%$ of cases; this could be due to geographical variation in the distribution of the organism.

In vitro susceptibility testing of Nocardia species isolates from patients showed imipenem (100\%) and amikacin $(99 \%)$ to be the most effective treatment choice for nocardial infections. Sensitivity to cotrimaxazole, ofloxacin, amoxicillin-clavulanic acid and erythromycin was $76.5 \%, 60 \%, 45.3 \%$ and $24 \%$ respectively. Although cotrimaxazole is considered the drug of choice for the treatment of nocardial infections, a moderate degree $(23.5 \%)$ of resistance was observed in this study. Various other studies have also reported an increased resistance of Nocardia species to drugs containing sulfonamide $[7,9,19]$.

\section{References}

1. Saubolle MA and Sussland D (2003) Nocardiosis: Review of clinical and laboratory experience. J Clin Microbiol 41: 4497-4501.

2. Georghious PR and Blacklock ZM (1992) Infection with Nocardiosis species in Queensland. A review of 102 clinical isolates. Med J Aust 156: 692-697.

3. Manikandan P, Bhaskar M, Ravathi R, Anita R, Abarna LLR, Narendran V (2007) Isolation and antimicrobial susceptibility pattern of Nocardia among people with culture proven ocular infections attending a tertiary care eye hospital in Tamilnadu, South India. Eye 21: 1102-1108.

4. Mari B, Monton C, Mariscal D, Lujan M, Sala M, Domingo C (2001) Pulmonary Nocardiosis: Clinical experience in ten cases. Respiration 68: 382-388.

5. McNeil MM, Brown JM, Georghious PR, Allworth AM, Blacklock ZM (1992) Infections due to Nocardia transvalensis: clinical spectrum and antimicrobial therapy. Clin Inf Dis 15: 453-463.

6. Yildiz O, Alp E, Tokgoz B, Tucer B, Aygen B, Sumerkan B, Couble A, Boiron P, Doganay M (2005) Nocaardiosis in a teaching hospital in the central Anatolia region of Turkey: treatment and outcomes. Clin Microbiol Infect 11: 495-499. 
7. Matulionyte R, Rohner P, Uckay I, Lew D, Garbino J (2004) Secular trends of Nocardia infections over 15 years in a tertiary care hospital. J Clin Pathol 57: 807-812.

8. Subhash HS, Christopher DJ, Roy A, Cherian AM (2001) Pulmonary nocardiosis in human immunodeficiency virus infection: a tuberculosis mimic. J Postgrad Med 47: 30-32.

9. Maraki S, Scoulica E, Nioti E, Tselentis Y (2009) Nocardial infections in Crete, Greece: review of fifteen cases from 2003 to 2007. Scand J Infect Dis 41: 122-127.

10. Mootsikapun P, Intarapoka B, Liawnoraset W (2005) Nocardiosis in Srinagarind Hospital, Thailand: review of cases from 1996-2001. Int J Infect Dis 9: 154-158.

11. Mirza SH and Campbell C (1994) Mycetoma caused by Nocardia transvalensis. J Clin Pathol 47: 85-86.

12. Amanullah F and Salahuddin N (2008) Nocardiosis with psoas abscess: an unusual presentation in an 8-year-old. Infect Dis J 17: 105-107.

13. Zubairi AB, Ashraf M, Anwar-ul-Huda (2006) Necrotizing nocardia pneumonia in an immuno-compromised male. J Coll Physicians Surg Pak 16: 162-163.

14. Murray PR, Baron EJ, Pfaller MA, Tenover FC, Yolken RH (1999) Manual of clinical Microbiology, $7^{\text {th }}$ edition. Washington DC: ASM press. 370-398.

15. Kiska DL, Hicks K, Pettit DJ (2002) Identification of medically relevant Nocardia species with an abbreviated battery of tests. J Clin Microbiol 40: 1346-1351.

16. Farina C, Boiron P, Ferrari I, Provost F, Goglio A (2001) Report of human Nocardiosis in Italy between 1993 and 1997. Eur J Epidemiol; 17: 1019-1022.
17. Pintado V, Mampaso EG, Fortun J, Meseguer MA, Cobo J, Navas E, Querada, Davila PM, Moreno S (2003) Infection with Nocardia species: Clinical spectrum of disease and species distribution in Madrid, Spain, 1978-2001. Infection 30: 338-340.

18. Kageyama A, Yazawa K, Ishikawa J, Hotta K, Nishimura K, Mikami Y (2004) Nocardial infections in Japan from 19922001, including the first report of infection by Nocardia transvalencesis. Eur J Epidemiol 19: 383-389.

19. Hitti W and Wolff M (2005) Two cases of multidrugresistant Nocardia farcinica infection in immunosuppressed patients and implications for empiric therapy. Eur J Clin Microbiol Infect Dis 24: 142-144.

\author{
Corresponding author \\ Safia Bibi \\ Research Officer \\ PMRC Research Centre \\ Jinnah Postgraduate Medical Centre, Karachi \\ Pakistan \\ Telephone: +92-332-3271256 \\ Email: safia_akuh@yahoo.com
}

Conflict of interests: No conflict of interests is declared. 